\title{
Penerapan Value Engineering Pada Mesin Molen Cor Kapasitas 50 Kg
}

\author{
Hisyam Hafis Achmad $^{* 1)}$ dan Hari Supriyanto ${ }^{2)}$ \\ 1) Jurusan Teknik Industri, Fakultas Teknologi Industri, Institut Teknologi Adhi Tama Surabaya \\ Jl. Arief Rahman Hakim No. 100, Klampis, Ngasem, Sukolilo, Surabaya \\ 1)keldymana@gmail.com
}

\begin{abstract}
Abstrak
Pada mesin molen cor kapasitas $50 \mathrm{~kg}$, banyak ditemukan beberapa komponen yang mengalami trouble. Perancangan mesin molen diawali dengan tahap informasi dimana pada tahap ini diketahui komponen kritisnya adalah tabung solar, roda pemindah, sirip pengaduk, knalpot, pulley, kerangka bawah. Kemudian masuk kedalam tahap analisa dilakukan secara analisa teknik dengan membuat diagram FAST (Function Analysis System Technique) dan analisa biaya yang dihasilkan bahwa biaya kerugian kerusakan sebesar Rp. 54.700.000. Kemudian pada tahap kreatif dimunculkan berbagai konsep perbaikan untuk tiap komponen yang kritis yang kemudian pada tahap evaluasi dilakukan perhitungan value untuk memilih konsep mana yang terbaik. Hasil yang diperoleh adalah komponen tabung solar diperbaiki dengan diganti dengan bahan plastik, kerangka bawa diberi penguat pada sikusikunya, sirip pengaduk diberi penguat dengan besi betoneser, knalpot dipendekkan dan dihadapkan kebawah, Pulley dan roda pemindah ditambah masing-masing satu unit. Kemudian hasil Analisa biaya setelah dilakukannya perbaikan adalah sebesar Rp. 3.190.000.
\end{abstract}

Kata Kunci : Mesin molen cor, Value Engineering, Komponen Kritis, FAST

\section{Pendahuluan (Introduction)}

Mesin molen memiliki berbagai macam variasi ukuran dan kapasitas untuk menampung adonan semen. Diantaranya mesin molen kapasitas $25 \mathrm{KG}, 40 \mathrm{KG}, 50 \mathrm{KG}$, dan seukuran truck atau biasa dikenal truck concrete mixer dengan kapasitas $3 \mathrm{~m}^{3}$ (kubik) hingga $7 \mathrm{~m}^{3}$ (kubik).

Dalam penggunaannya, mesin molen kapasitas $50 \mathrm{KG}$ yang paling sering digunakan oleh para kontraktor, karena ukurannya yang fleksibel bisa digunakan untuk akses tempat yang sempit dan cocok untuk digunakan dalam proses pengecoran bangunan berskala besar maupun kecil (Bytheway, 2007).

Karena harganya yang cukup mahal, pihak kontraktor biasanya lebih memilih untuk menyewa daripada membeli mesin molen cor kapasitas $50 \mathrm{Kg}$. Hal ini menjadi peluang bagi pemilik persewaan untuk memberikan pelayanan terbaik dan menjaga mutu dari molen yang disewakan.

Dalam pengaplikasiannya, mesin molen cor kapasitas $50 \mathrm{KG}$ ini memiliki komponen yang sering trouble dan kritis mengalami kerusakan (Krisna, 2020). Diantaranya kerangka bawah, roda dan knalpot pada molen. Selain itu harga jual mesin molen baru mengalami kenaikan yang cukup tinggi dengan harga Rp. 13.700 .000

Untuk penyelesaian masalah ini digunakan metode yang tepat dan optimal dengan mengetahui komponen-komponen mana saja pada mesin molen yang paling kritis mengalami kerusakan dan membuat perbaikan setelah diketahui unsur permasalahannya.

Adapaun metode yang tepat digunakan pada permasalah mesin molen ini yaitu dengan mengimplementasikan metode Function Analysis System Tecnique (FAST). FAST diagram digunakan untuk mengidentifikasi fungsi-fungsi komponen pada molen sebelum masuk analisa fungsi. Setelah didapatkan hasil dari metode FAST, selanjutnya akan dilakukan pengembangan produk yang dilihat dari komponen kritisnya. Analisa biaya kerugian sebelum dilakukannya perbaikan menghabiskan biaya Rp. 54.700.000 selama 6 bulan, yang mana angka tersebut sangat besar dan harus dilakukan upaya improvisasi untuk mereduksi biaya kerugian karena adanya komponen yang trouble tersebut. 


\section{Metode Penelitian (Methods)}

\subsection{Tahap Identifikasi Masalah}

Berikut adalah tahapan-tahapan metode penelitian yang menjelaskan tahapan identifikasi masalah yang dicapai oleh peneliti, diantaranya :

1. Identifikasi Masalah dan Tujuan Penelitian

Tahap ini menjelaskan bagaimana peneliti merumuskan masalah yang ada dan tujuan dari penelitian ini dibuat

2. Studi Pustaka

Kegiatan studi Pustaka dilakukan pada saat belajar didalam kelas ataupun mandiri dari berbagai sumber

3. Studi Lapangan

Kegiatan studi lapangan dilakukan di MAX-Rent anak usaha dari UD.Munajaya. Dengan menggunakan materi yang didapat dari berbagai sumber.

\subsection{Tahap Pengumpulan Data}

Pada tahap ini peneliti mengumpulkan data-data yang berkaitan dengan data pendukung untuk menyelesaikan permasalahan dalam penelitian ini. Data-data tersebut diperoleh dari proses observasi, wawancara dengan pihak terkait, dan melihat dokumentasi arsip perusahaan. Adapun metode pengumpulan data yang dipakai dalam penelitian ini sebagai berikut:

1. Data Primer

Data ini diambil secara langsung dengan melakukan pengamatan pada produk dan melakukan wawancara dengan pihak terkait

2. Data Sekunder

Peneliti melihat desain gambar bagian-bagian komponen pada produk dan daftar harga komponen-komponen pada produk. 


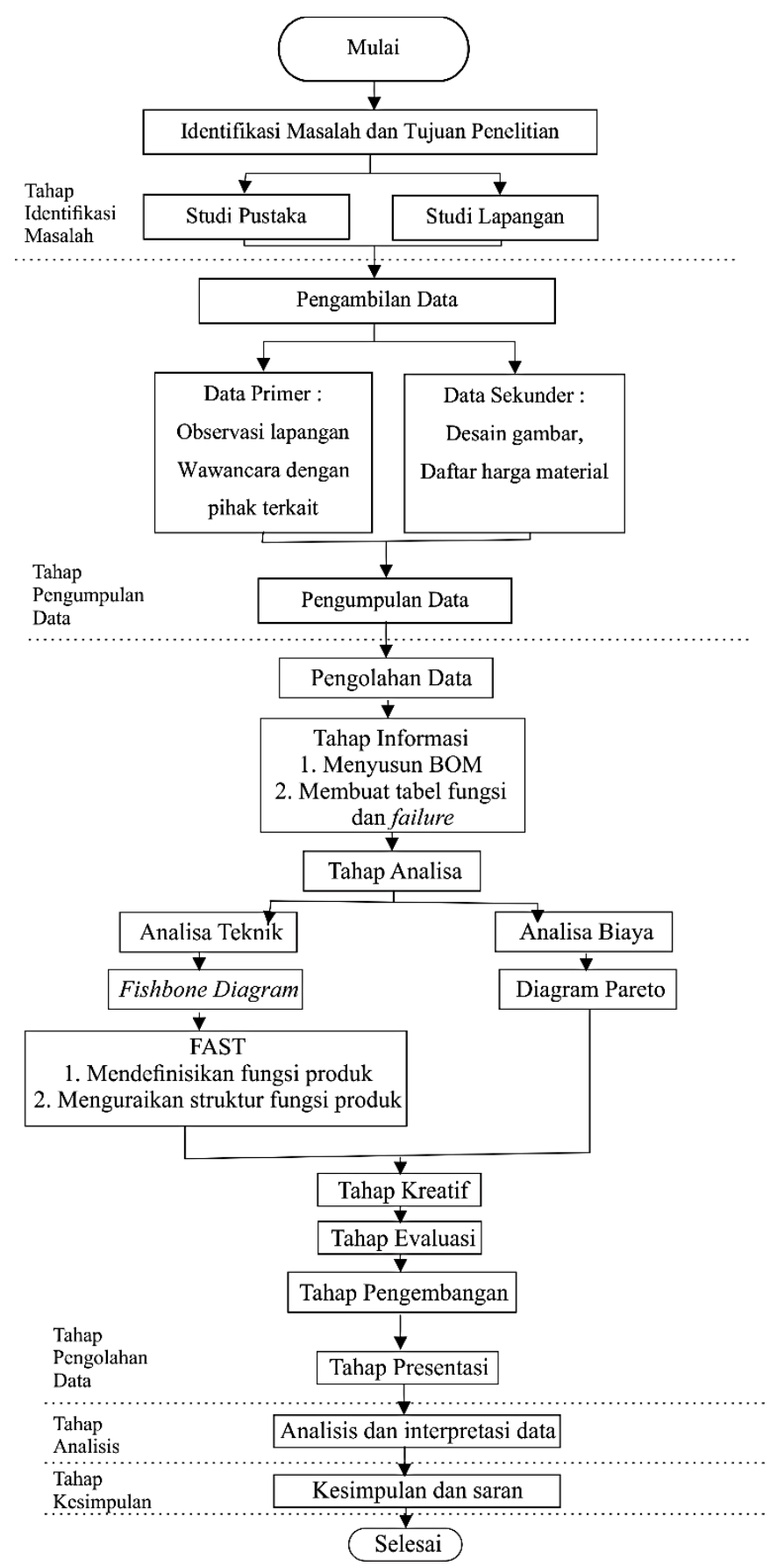

Gambar 1. Flowchart Metodologi Penelitian

\subsection{Tahap Pengolahan Data}

Pada tahap ini, peneliti melakukan pengolahan data terhadap data-data pendukung yang telah dikumpulkan dari perusahan untuk memecahkan permasalahan yang dialami dari penelitian ini dan mencapai tujuan yang diharapkan. Pada penelitian ini, peneliti melakukan pengolahan data dengan metode Function Analysis System Tecnique (FAST) dan Diagram Pareto (Younker, 2007). Dimana metode FAST dimaksutkan untuk menganalisa fungsi tertinggi dan terendah dari produk yang akan diteliti sehingga memunculkan biaya dan komponen kritis. Diagram Pareto digunakan untuk mengetahui komponen mana yang diprioritaskan untuk diperbaiki dan dampaknya yang paling besar.

\subsection{Tahap Analisis Data}

Setelah melakukan pengolahan data, tahap selanjutnya adalah melakukan tahap analisa pada data. Hal ini dilakukan untuk mengintrepretasikan secara rinci dari hasil pengolahan data yang dilakukan. 


\subsection{Tahap Kesimpulan}

Tahap terakhir adalah tahap kesimpulan, dimana pada tahap ini dilakukan penarikan kesimpulan dan memberikan saran untuk memperoleh tujuan penelitian yang akan dicapai.

\section{Hasil dan Pembahasan (Results and Discussions)}

\subsection{Tahap Informasi}

Berdasarakan hasil dan pengamatan dilapangan dan wawancara yang dilakukan pada pekerja, ditemukan adanya beberapa komponen yang sering mengalami trouble. Sehingga hal ini menjadi kerugian bagi pemilik usaha dan juga konsumen yang menyewa. Diantara komponen tersebut adalah knalpot, tabung solar, roda, kerangka bawah, sirip pengaduk, dan pulley.

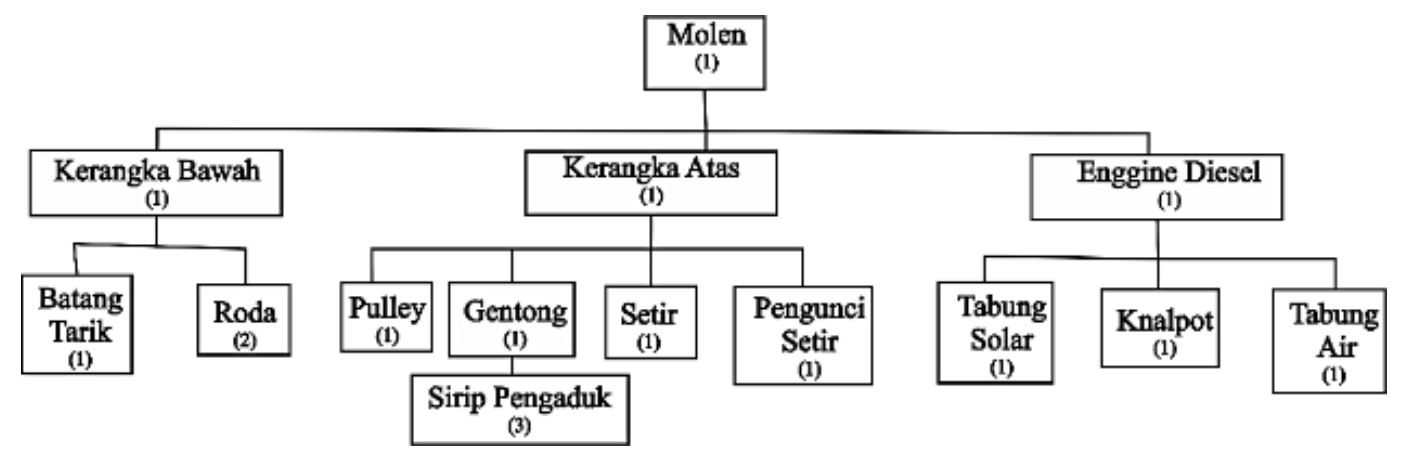

Gambar 2. BOM Mesin Molen

\subsection{Tahap Analisa}

\subsubsection{Analisa Teknik}

Pada FAST diagram mesin molen cor yang menjadi fungsi terendahnya adalah menyalakan engine. Sedangkan yang menjadi fungsi tertingginya adalah menuang adonan semen. Jika dilihat dari fungsi terendahnya (HOW) mengapa menyalakan engine? Karena untuk memutar roda gigi. Mengapa memutar roda gigi? Karena untuk memutar pully. Mengapa memutar pully? Karena untuk memutar gentong. Mengapa memutar gentong? Supaya bisa memiringkan gentong. Mengapa memiringkan gentong? Untuk memudahkan memasukkan bahan dan mengaduk adonan semen. Mengapa mengaduk adonan semen? Untuk persiapan dituangkan dengan memiringkan gentong. Mengapa memiringkan gentong? Untuk menuang adonan semen.

Jika dilihat dari fungsi tertingginya (WHY) bagaimana menuang adonan semen? Dengan cara memiringkan gentong. Bagaimana memiringkan gentong? Dengan cara mengaduk semen terlebih dahulu. Bagaimana cara mengaduk semen? Dengan cara memasukkan bahan dan memiringkan gentong. Bagaimana memiringkan gentong? Dengan cara gentong diputar terlebih dahulu. Bagaimana memutar gentong? Dengan memutar pully. Bagaimana memutar pully? Dengan cara memutar roda gigi. Bagaimana memutar roda gigi? Dengan cara menyalakan engine 


\subsubsection{Analisa Biaya}

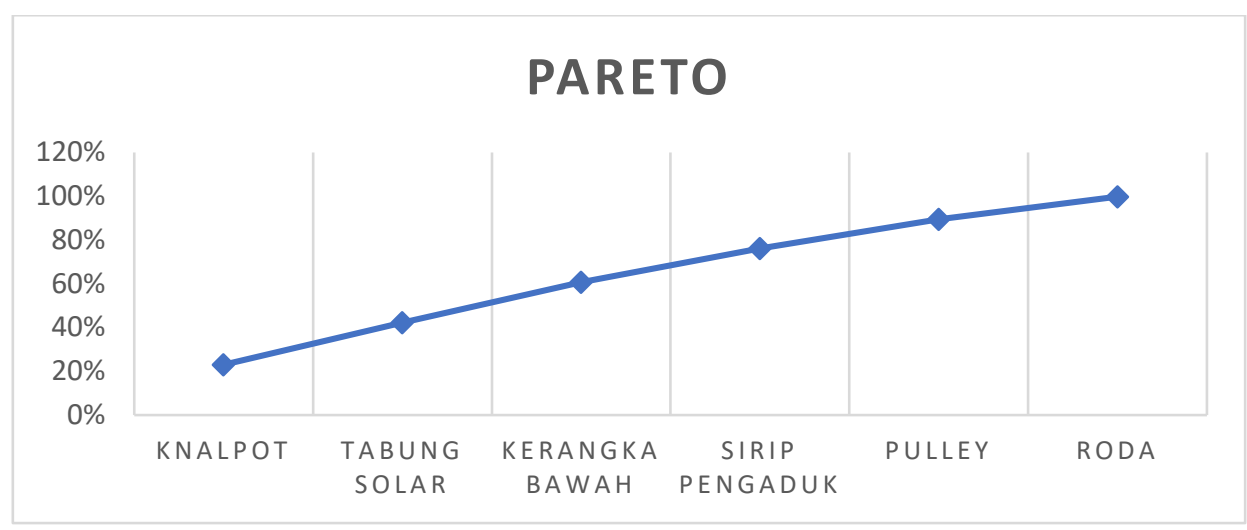

Gambar 3. Diagram Pareto

Pada grafik diagram pareto dapat diketahui komponen mana yang perlu diprioritaskan untuk diperbaiki terlebih dahulu apabila ada trouble yang muncul bersamaan (Harsita, 2019). Yang pertama adalah komponen knalpot, kedua tabung solar, ketiga kerangka bawah, keempat sirip pengaduk, kelima pulley, keenam roda.

\subsection{Tahap Kreatif}

Pada tahap ini peneliti memberikan alternatif perbaikan komponen yang kritis pada mesin molen. Dasar dari tahap kreatif adalah diambil dari ide kreatif dari peneliti dan seluruh personil dari pihak lapangan MAX-Rent (UD.Munajaya) serta pengalaman perbaikan yang pernah dilakukan oleh personil dari pihak lapangan.

Tabel 1. Alasan \& Biaya Alternatif Perbaikan

\begin{tabular}{|c|c|c|c|}
\hline No & Komponen & Alternatif & Alasan \\
\hline \multirow{3}{*}{1} & \multirow{3}{*}{ Knalpot } & 1. Dipendekkan & Mengurangi beban getaran \\
\hline & & 2. Dihadapkan bawah & Agar tidak kemasukan air \\
\hline & & $\begin{array}{l}\text { 3. Dipendekkan \& } \\
\text { diahadapkan bawah }\end{array}$ & $\begin{array}{l}\text { Mengurangi beban getaran dan } \\
\text { tidak kemasukan air }\end{array}$ \\
\hline \multirow{3}{*}{2} & \multirow{3}{*}{ Tabung solar } & 1. Ganti tabung & Agar tidak mudah bocor \\
\hline & & 2. Ditinggikan & $\begin{array}{l}\text { Agar bisa memaksimalkan } \\
\text { masuknya solar }\end{array}$ \\
\hline & & $\begin{array}{l}\text { 3. Ganti tabung \& } \\
\text { ditinggikan }\end{array}$ & $\begin{array}{l}\text { Agar tidak mudah bocor \& bisa } \\
\text { memaksimalkan masuknya solar }\end{array}$ \\
\hline \multirow{3}{*}{3} & \multirow{3}{*}{$\begin{array}{l}\text { Kerangka } \\
\text { Bawah }\end{array}$} & 1. Siku diperkuat & $\begin{array}{l}\text { Agar kuat menahan beban } \\
\text { gentong \& engine }\end{array}$ \\
\hline & & 2. Ganti bentuk & Kuat menahan beban gentong \\
\hline & & $\begin{array}{l}\text { 3. Siku diperkuat \& } \\
\text { ganti bentuk }\end{array}$ & $\begin{array}{l}\text { Agar kuat menahan beban } \\
\text { gentong \& engine }\end{array}$ \\
\hline \multirow{3}{*}{4} & \multirow{3}{*}{$\begin{array}{c}\text { Sirip } \\
\text { Pengaduk }\end{array}$} & 1. Ganti bahan & Tidak mudah patah \\
\hline & & 2. Diperkuat & Tidak mudah patah \\
\hline & & $\begin{array}{l}\text { 3. Ganti bahan \& } \\
\text { diperkuat }\end{array}$ & Tidak mudah patah \\
\hline \multirow{2}{*}{5} & \multirow{2}{*}{ Pulley } & 1. Ditambah 1 & Agar putaran lebih ringan \\
\hline & & 2. Ditambah 2 & Agar putaran lebih ringan \\
\hline
\end{tabular}




\begin{tabular}{|l|l|l|l|}
\hline \multirow{2}{*}{6} & \multirow{2}{*}{ Roda } & 1. Ditambah 1 & Agar mudah dipindahkan \\
\cline { 3 - 4 } & & 2. Ditambah 2 & Agar mudah dipindahkan \\
\hline
\end{tabular}

\subsection{Tahap Evaulasi}

\subsubsection{Value Knalpot}

Berikut adalah tabel 4.10 yang menunjukkan penilaian performance pada tiap alternatif perbaikan berdasarkan tiga kriteria yang telah ditentukan dari komponen knalpot oleh kelima responden di MAXRent.

Tabel 2. Value Knalpot

\begin{tabular}{|c|c|c|c|c|c|c|c|c|c|c|c|c|c|c|c|c|}
\hline \multicolumn{17}{|c|}{ Knalpot } \\
\hline \multirow{3}{*}{ Alternatif } & \multicolumn{15}{|c|}{ Karyawan } & \multirow{3}{*}{ Performance } \\
\hline & \multicolumn{3}{|c|}{ P.Mujib } & \multicolumn{3}{|c|}{ P.Heru } & \multicolumn{3}{|c|}{ Feri } & \multicolumn{3}{|c|}{ Mundir } & \multicolumn{3}{|c|}{ Rama } & \\
\hline & K1 & K2 & K3 & K1 & K2 & K3 & K1 & K2 & K3 & K1 & K2 & K3 & K1 & K2 & K3 & \\
\hline 0 & 2 & 1 & 2 & 1 & 3 & 2 & 1 & 2 & 1 & 3 & 2 & 1 & 2 & 1 & 3 & 27 \\
\hline 1 & 5 & 7 & 5 & 6 & 8 & 5 & 7 & 5 & 6 & 8 & 5 & 7 & 5 & 6 & 8 & 93 \\
\hline 2 & 7 & 6 & 8 & 6 & 7 & 7 & 6 & 8 & 6 & 7 & 7 & 6 & 8 & 6 & 7 & 102 \\
\hline 3 & 10 & 8 & 9 & 8 & 7 & 10 & 8 & 7 & 9 & 7 & 10 & 8 & \begin{tabular}{l|l}
9 \\
\end{tabular} & 9 & 7 & 126 \\
\hline
\end{tabular}

Value $=$ Performance $/$ Cost

- Alternatif $0=$ Tidak diperbaiki

- Alternatif 1 = Knalpot dipendekkan ukurannya

- Alternatif $2=$ Knalpot dihadapkan bawah

- Alternatif 3 = Knalpot dipendekkan \& dihadapkan bawah

$$
\begin{aligned}
& \mathrm{V} 0=\mathrm{P} 0 / \mathrm{C} 0=1 \\
& \mathrm{~V} 0=27 \times \mathrm{Px} / 150000=\mathrm{Px}=5555.6 \\
& \mathrm{~V} 0=\mathrm{P} 0 / \mathrm{C} 0=5555.6 \times 27 / 150000=1.0 \\
& \mathrm{~V} 1=\mathrm{P} 1 / \mathrm{C} 1=5555.6 \times 93 /(150000+25000)=3.0 \\
& \mathrm{~V} 2=\mathrm{P} 2 / \mathrm{C} 2=5555.6 \times 102 /(150000+25000)=3.2 \\
& \mathrm{~V} 3=\mathrm{P} 3 / \mathrm{C} 3=5555.6 \times 126 /(150000+50000)=3.5
\end{aligned}
$$

Dari keempat alternatif yang dihitung value nya, didapat nilai value yang tertinggi pada alternatif yang ketiga. Sehingga perbaikan dilakukan dengan cara knalpot dipendekkan \& dihadapkan bawah.

\begin{tabular}{|c|c|c|c|c|c|c|c|c|c|c|c|c|c|c|c|c|}
\hline \multicolumn{17}{|c|}{ Tabung Solar } \\
\hline \multirow{3}{*}{ Alternatif } & \multicolumn{15}{|c|}{ Karyawan } & \multirow{3}{*}{ Performance } \\
\hline & \multicolumn{3}{|c|}{ P.Mujib } & \multicolumn{3}{|c|}{ P.Heru } & \multicolumn{3}{|c|}{ Feri } & \multicolumn{3}{|c|}{ Mundir } & \multicolumn{3}{|c|}{ Rama } & \\
\hline & K1 & $\mathrm{K} 2$ & K3 & K1 & K2 & K3 & K1 & K2 & K3 & K1 & K2 & K3 & K1 & K2 & K3 & \\
\hline 0 & 1 & 1 & 2 & 1 & 3 & 2 & 1 & 2 & 1 & 2 & 1 & 1 & 2 & 1 & 3 & 24 \\
\hline 1 & 3 & 4 & 4 & 6 & 3 & 5 & 7 & 5 & 4 & 4 & 6 & 7 & 5 & 6 & 8 & 77 \\
\hline 2 & 7 & 7 & 6 & 8 & 8 & 7 & 6 & 8 & 7 & 6 & 8 & 6 & 8 & 6 & 7 & 105 \\
\hline 3 & 10 & 9 & 10 & 10 & 9 & 10 & 8 & 7 & 9 & \begin{tabular}{|l|l}
10 \\
\end{tabular} & \begin{tabular}{l|l|}
10 & \\
\end{tabular} & 8 & 9 & 9 & 7 & 135 \\
\hline
\end{tabular}

\subsubsection{Value Tabung Solar}

Berikut adalah tabel 4.11 yang menunjukkan penilaian performance pada tiap alternatif perbaikan berdasarkan tiga kriteria yang telah ditentukan dari komponen tabung solar oleh kelima responden di MAX-Rent.

Tabel 3. Value Tabung Solar

Value $=$ Performance $/$ Cost

- Alternatif $0=$ Tidak diperbaiki

- Alternatif $1=$ Tabung diganti bahan

- Alternatif 2 = tabung solar ditinggikan posisinya 
- Alternatif $3=$ Tabung diganti bahan \& ditinggikan posisinya

$$
\begin{aligned}
& \mathrm{V} 0=\mathrm{P} 0 / \mathrm{C} 0=1 \\
& \mathrm{~V} 0=24 \times \mathrm{Px} / 150000=\mathrm{Px}=6250 \\
& \mathrm{~V} 0=\mathrm{P} 0 / \mathrm{C} 0=6250 \times 24 / 150000=1.0 \\
& \mathrm{~V} 1=\mathrm{P} 1 / \mathrm{C} 1=6250 \times 77 /(25000)=2.8 \\
& \mathrm{~V} 2=\mathrm{P} 2 / \mathrm{C} 2=6250 \times 105 /(150000+25000)=3.8 \\
& \mathrm{~V} 3=\mathrm{P} 3 / \mathrm{C} 3=6250 \times 135 /(50000)=4.2
\end{aligned}
$$

Dari keempat alternatif yang dihitung value nya, didapat nilai value yang tertinggi pada alternatif yang ketiga. Sehingga perbaikan dilakukan dengan cara tabung diganti bahan \& ditinggikan posisinya.

\begin{tabular}{|c|c|c|c|c|c|c|c|c|c|c|c|c|c|c|c|c|}
\hline \multicolumn{17}{|c|}{ Kerangka Bawah } \\
\hline \multirow{3}{*}{ Alternatif } & \multicolumn{15}{|c|}{ Karyawan } & \multirow{3}{*}{ Performance } \\
\hline & \multicolumn{3}{|c|}{ P.Mujib } & \multicolumn{3}{|c|}{ P.Heru } & \multicolumn{3}{|c|}{ Feri } & \multicolumn{3}{|c|}{ Mundir } & \multicolumn{3}{|c|}{ Rama } & \\
\hline & K1 & K2 & K3 & K1 & K2 & K3 & K1 & K2 & K3 & K1 & K2 & K3 & K1 & K2 & K3 & \\
\hline 0 & 2 & 1 & 1 & 1 & 1 & 2 & 1 & 2 & 1 & 2 & 1 & 1 & 2 & 1 & 3 & 22 \\
\hline 1 & 9 & 6 & 8 & 6 & 8 & 9 & 7 & 9 & 8 & 4 & 8 & 7 & 8 & 9 & 8 & 114 \\
\hline 2 & 8 & 7 & 6 & 8 & 8 & 7 & 6 & 8 & 7 & 6 & 8 & 6 & 8 & 6 & 7 & 106 \\
\hline 3 & 9 & 9 & 8 & 9 & 7 & 10 & 8 & 7 & 9 & 10 & 10 & 8 & 9 & 9 & 7 & 129 \\
\hline
\end{tabular}

\subsubsection{Value Kerangka Bawah}

Berikut adalah tabel 4.12 yang menunjukkan penilaian performance pada tiap alternatif perbaikan berdasarkan tiga kriteria yang telah ditentukan dari komponen kerangka bawah oleh kelima responden di MAX-Rent.

Tabel 4. Value Kerangka Bawah

Value $=$ Performance $/$ Cost

- Alternatif $0=$ Tidak diperbaiki

- Alternatif $1=$ Siku kerangka bawah diperkuat

- Alternatif $2=$ diganti bentuk

- Alternatif $3=$ Siku kerangka bawah diperkuat diganti bentuk

$\mathrm{V} 0=\mathrm{P} 0 / \mathrm{C} 0=1$

$\mathrm{V} 0=22 \mathrm{x} \mathrm{Px} / 2000000=>\mathrm{Px}=90909.1$

$\mathrm{V} 0=\mathrm{P} 0 / \mathrm{C} 0=90909.1 \times 22 / 2000000=1.0$

$\mathrm{V} 1=\mathrm{P} 1 / \mathrm{C} 1=90909.1 \times 114 /(2000000+500000)=4.1$

$\mathrm{V} 2=\mathrm{P} 2 / \mathrm{C} 2=90909.1 \times 106 /(2000000+1000000)=3.2$

$\mathrm{V} 3=\mathrm{P} 3 / \mathrm{C} 3=90909.1 \times 129 /(2000000+1000000+500000)=3.4$

Dari keempat alternatif yang dihitung value nya, didapat nilai value yang tertinggi pada alternatif yang pertama. Sehingga perbaikan dilakukan dengan cara Siku kerangka bawah diperkuat

\subsubsection{Value Sirip Pengaduk}

Berikut adalah tabel 4.13 yang menunjukkan penilaian performance pada tiap alternatif perbaikan berdasarkan tiga kriteria yang telah ditentukan dari komponen sirip pengaduk oleh kelima responden di MAX-Rent. 
Tabel 5. Value Sirip Pengaduk

\begin{tabular}{|c|c|c|c|c|c|c|c|c|c|c|c|c|c|c|c|c|}
\hline \multicolumn{17}{|c|}{ Sirip Pengaduk } \\
\hline \multirow{3}{*}{ Alternatif } & \multicolumn{15}{|c|}{ Karyawan } & \multirow{3}{*}{ Performance } \\
\hline & \multicolumn{3}{|c|}{ P.Mujib } & \multicolumn{3}{|c|}{ P.Heru } & \multicolumn{3}{|c|}{ Feri } & \multicolumn{3}{|c|}{ Mundir } & \multicolumn{3}{|c|}{ Rama } & \\
\hline & K1 & K2 & K3 & K1 & K2 & K3 & K1 & K2 & K3 & K1 & K2 & K3 & K1 & K2 & K3 & \\
\hline 0 & 1 & 1 & 1 & 1 & 1 & 2 & 1 & 2 & 1 & 1 & 1 & 1 & 1 & 1 & 3 & 19 \\
\hline 1 & 4 & 5 & 6 & 6 & 5 & 3 & 7 & 4 & 4 & 5 & 6 & 4 & 8 & 9 & 5 & 81 \\
\hline 2 & 8 & 7 & 6 & 8 & 6 & 7 & 6 & 8 & 8 & 7 & 6 & 8 & 6 & 6 & 7 & 104 \\
\hline 3 & 9 & 10 & 9 & 9 & 6 & 10 & 8 & 7 & 9 & 10 & 9 & 9 & 6 & 9 & 7 & 127 \\
\hline
\end{tabular}

Value $=$ Performance $/$ Cost

- Alternatif $0=$ Tidak diperbaiki

- Alternatif $1=$ Sirip pengaduk diganti bahan lain

- Alternatif 2 = Sirip pengaduk diberi lapisan penguat

- Alternatif $3=$ Sirip pengaduk diganti bahan lain \& diberi lapisan penguat

$$
\begin{aligned}
& \mathrm{V} 0=\mathrm{P} 0 / \mathrm{C} 0=1 \\
& \mathrm{~V} 0=19 \times \mathrm{Px} / 600000=>\mathrm{Px}=31578.9 \\
& \mathrm{~V} 0=\mathrm{P} 0 / \mathrm{C} 0=31578.9 \times 19 / 600000=1.0 \\
& \mathrm{~V} 1=\mathrm{P} 1 / \mathrm{C} 1=31578.9 \times 81 / 900000=2.8 \\
& \mathrm{~V} 2=\mathrm{P} 2 / \mathrm{C} 2=31578.9 \times 104 /(600000+450000)=3.1 \\
& \mathrm{~V} 3=\mathrm{P} 3 / \mathrm{C} 3=31578.9 \times 127 /(900000+450000)=3.0
\end{aligned}
$$

Dari keempat alternatif yang dihitung value nya, didapat nilai value yang tertinggi pada alternatif yang kedua. Sehingga perbaikan dilakukan dengan cara sirip pengaduk diberi lapisan penguat

\begin{tabular}{|c|c|c|c|c|c|c|c|c|c|c|c|c|c|c|c|c|}
\hline \multicolumn{17}{|c|}{ Pulley } \\
\hline \multirow{3}{*}{ Alternatif } & \multicolumn{15}{|c|}{ Karyawan } & \multirow{3}{*}{ Performance } \\
\hline & \multicolumn{3}{|c|}{ P.Mujib } & \multicolumn{3}{|c|}{ P.Heru } & \multicolumn{3}{|c|}{ Feri } & \multicolumn{3}{|c|}{ Mundir } & \multicolumn{3}{|c|}{ Rama } & \\
\hline & K1 & K2 & K3 & K1 & K2 & K3 & K1 & K2 & K3 & K1 & K2 & K3 & K1 & K2 & K3 & \\
\hline 0 & 1 & 3 & 1 & 3 & 3 & 2 & 1 & 1 & 3 & 1 & 3 & 3 & 4 & 1 & 3 & 33 \\
\hline 1 & 10 & 8 & 7 & 8 & 8 & 9 & 7 & 10 & 8 & 7 & 8 & 8 & 8 & 9 & 8 & 123 \\
\hline 2 & 8 & 7 & 8 & 8 & 8 & 7 & 6 & 8 & 7 & 8 & 8 & 8 & 6 & 6 & 7 & 110 \\
\hline
\end{tabular}

\subsubsection{Value Pulley}

Berikut adalah tabel 4.14 yang menunjukkan penilaian performance pada tiap alternatif perbaikan berdasarkan tiga kriteria yang telah ditentukan dari komponen pulley oleh kelima responden di MAXRent.

Tabel 6. Value Pulley

Value $=$ Performance $/$ Cost

- Alternatif $0=$ Tidak diperbaiki

- Alternatif $1=$ Pulley ditambah 1 unit lagi

- Alternatif $2=$ Pulley ditambah 2 unit lagi

$$
\begin{aligned}
& \mathrm{V} 0=\mathrm{P} 0 / \mathrm{C} 0=1 \\
& \mathrm{~V} 0=33 \times \mathrm{Px} / 500000=\mathrm{Px}=15151.5 \\
& \mathrm{~V} 0=\mathrm{P} 0 / \mathrm{C} 0=15151.5 \times 33 / 500000=1.0 \\
& \mathrm{~V} 1=\mathrm{P} 1 / \mathrm{C} 1=15151.5 \times 123 /(500000+500000)=1.9 \\
& \mathrm{~V} 2=\mathrm{P} 2 / \mathrm{C} 2=15151.5 \times 110 /(500000+500000+500000)=1.1
\end{aligned}
$$

Dari ketiga alternatif yang dihitung value nya, didapat nilai value yang tertinggi pada alternatif yang pertama. Sehingga perbaikan dilakukan dengan cara Pulley ditambah 1 unit lagi. 


\subsubsection{Value Roda Pemindah Molen}

Berikut adalah tabel 4.15 yang menunjukkan penilaian performance pada tiap alternatif perbaikan berdasarkan tiga kriteria yang telah ditentukan dari komponen roda pemindah oleh kelima responden di MAX-Rent.

Tabel 7. Value Roda Pemindah

\begin{tabular}{|c|c|c|c|c|c|c|c|c|c|c|c|c|c|c|c|c|}
\hline \multicolumn{17}{|c|}{ Roda Pemindah Molen } \\
\hline \multirow{3}{*}{ Alternatif } & \multicolumn{15}{|c|}{ Karyawan } & \multirow{3}{*}{ Performance } \\
\hline & \multicolumn{3}{|c|}{ P.Mujib } & \multicolumn{3}{|c|}{ P.Heru } & \multicolumn{3}{|c|}{ Feri } & \multicolumn{3}{|c|}{ Mundir } & \multicolumn{3}{|c|}{ Rama } & \\
\hline & K1 & K2 & K3 & K1 & K2 & K3 & K1 & K2 & K3 & K1 & K2 & K3 & K1 & K2 & K3 & \\
\hline 0 & 2 & 3 & 5 & 3 & 4 & 2 & 1 & 2 & 2 & 3 & 5 & 3 & 4 & 1 & 3 & 43 \\
\hline 1 & 9 & 6 & 7 & 6 & 8 & 9 & 7 & 9 & 9 & 6 & 7 & 6 & 8 & 9 & 8 & 114 \\
\hline 2 & 7 & 7 & 6 & 8 & 6 & 7 & 6 & 8 & 7 & 7 & 6 & 8 & 6 & 6 & 7 & 102 \\
\hline
\end{tabular}

Value $=$ Performance $/$ Cost

- Alternatif $0=$ Tidak diperbaiki

- Alternatif $1=$ Roda ditambah 1 unit lagi

- $\quad$ Alternatif $2=$ Roda ditambah 2 unit lagi

$$
\begin{aligned}
& \mathrm{V} 0=\mathrm{P} 0 / \mathrm{C} 0=1 \\
& \mathrm{~V} 0=43 \times \mathrm{Px} / 200000=\mathrm{Px}=18181.8 \\
& \mathrm{~V} 0=\mathrm{P} 0 / \mathrm{C} 0=18181.8 \times 43 / 200000=1.0 \\
& \mathrm{~V} 1=\mathrm{P} 1 / \mathrm{C} 1=18181.8 \times 114 /(200000+100000)=1.8 \\
& \mathrm{~V} 2=\mathrm{P} 2 / \mathrm{C} 2=18181.8 \times 102 /(200000+100000+100000)=1.2
\end{aligned}
$$

Dari ketiga alternatif yang dihitung value nya, didapat nilai value yang tertinggi pada alternatif yang pertama. Sehingga perbaikan dilakukan dengan cara Pulley ditambah 1 unit lagi.

\subsection{Tahap Pengembangan}

Pada tahap ini dilakukan penerapan dari alternatif perbaikan tiap-tiap komponen pada mesin molen cor kapasitas $50 \mathrm{~kg}$ yang telah dipilih dalam bentuk desain gambar.

\subsubsection{Pengembangan Knalpot}

Pada pengembangan komponen knalpot terlihat perbedaan yang mencolok dari bentuk knalpot yang sebelumnya ukurannya tinggi dan menghadap keatas menjadi lebih pendek dan menghadap kebawah.

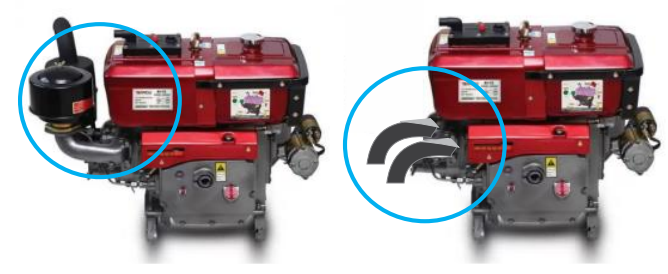

Gambar 4. Knalpot sebelum dan sesudah improvement 


\subsubsection{Pengembangan Tabung Solar}

Pada pengembangan komponen tabung solar terlihat perbedaan yang mencolok dari bentuk tabung solar yang sebelumnya posisinya lebih rendah menjadi lebih tinggi, serta bahan dasar yang sebelumnya besi dirubah menjadi tabung plastik yang putih transparan.
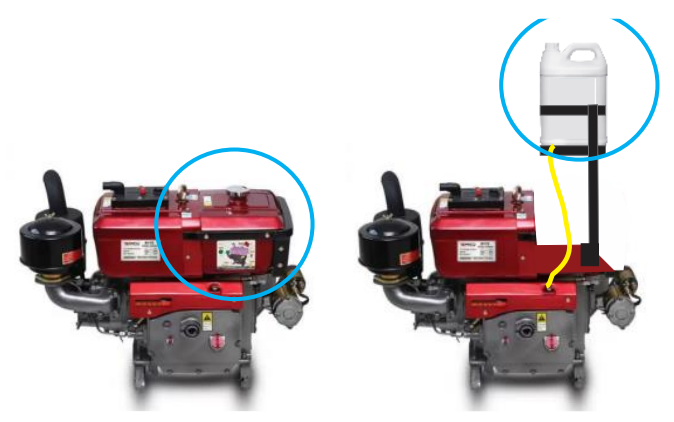

Gambar 5. Tabung solar sebelum dan sesudah improvement

\subsubsection{Pengembangan Kerangka Bawah}

Pada pengembangan komponen kerangka bawah terlihat perbedaan yang mencolok yaitu dari yang sebelumnya siku belakang masih polosan dan sekarang diberi penguat pada siku sehingga bisa menahan beban engine dan gentong molen.

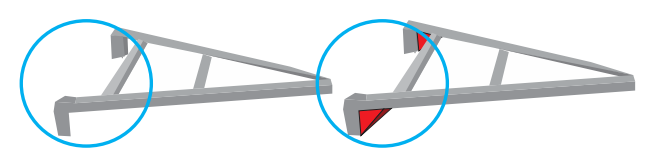

Gambar 6. Kerangka bawah sebelum dan sesudah improvement

\subsubsection{Pengembangan Sirip Pengaduk}

Pada pengembangan komponen sirip pengaduk terlihat perbedaan yang mencolok dari yang sebelumnya sirip besi yang awalnya dari besi yang tipis sekarang dilapisi dengan besi betoneser sehingga lebih tebal.
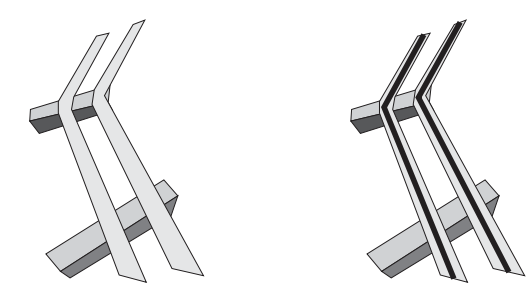

Gambar 7. Sirip pengaduk sebelum dan sesudah improvement

\subsubsection{Pengembangan Pulley}

Pada pengembangan pulley terlihat perbedaan yang mencolok dari jumlahnya yang awalnya hanya satu menjadi dua pulley. 


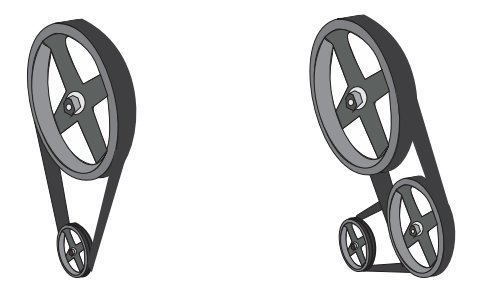

Gambar 8. Pulley sebelum dan sesudah improvement

\subsubsection{Pengembangan Roda Pemindah}

Pada pengembangan roda pemindah terlihat perbedaan yang mencolok dari yang awalnya pada bagian depan tidak ada rodanya, menjadi ada rodanya sehingga mesin molen memiliki tiga buah roda pemindah. Satu didepan dan dua dibelakang.
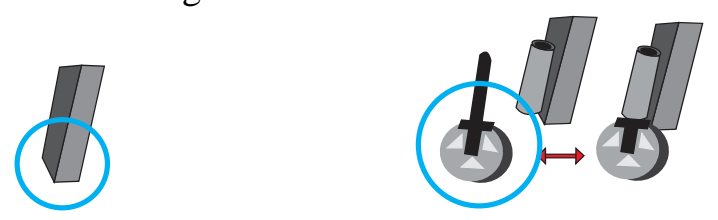

Gambar 9. Roda pemindah sebelum dan sesudah improvement

\subsection{Tahap Presentasi}

Tahap mempresentasikan hasil dari perbaikan yang telah dipilih dalam penerapan bentuk produk secara real.

\subsection{Penampakan Molen Setelah Diimprovisasi}

Pada bagian ini ditunjukkan pengaplikasian langsung dari alternatif perbaikan yang telah dipilih pada mesin molen cor kapasitas $50 \mathrm{~kg}$ di MAX-Rent (UD. Munajaya).

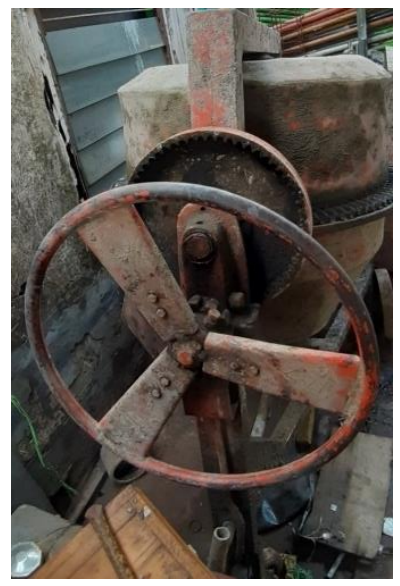

Gambar 10. Molen tampak depan 


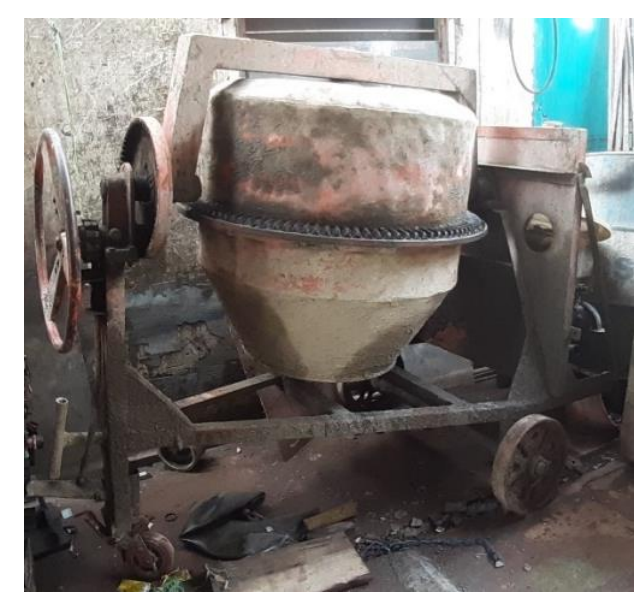

Gambar 11. Molen tampak samping

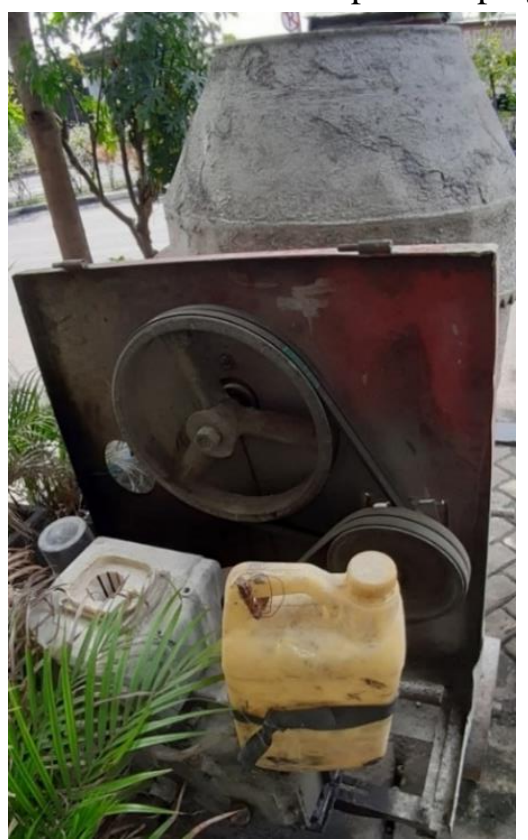

Gambar 12. Molen tampak belakang

\section{Kesimpulan (Conclusion)}

Dari pengolahan data yang telah penulis lakukan, peneliti dapat menarik kesimpulan sebagai berikut

1. Bill Of Materials pada mesin molen yang sudah dilakukan improvement adalah pada level 0 adalah Molen (1 unit); pada level 1 adalah kerangka bawah (1 unit), kerangka atas (1 unit), engine diesel (1 unit); pada level 2 adalah batang Tarik (1 unit), roda (3 unit), pulley (2 unit), gentong (1 unit), setir (1 unit), pengunci setir (1 unit), tabung solar (1 unit), knalpot (1 unit), tabung air (1 unit); pada level 3 adalah sirip pengaduk (3 unit)

2. FAST diagram pada mesin molen adalah Pada FAST diagram mesin molen cor yang menjadi fungsi terendahnya adalah menyalakan engine. Sedangkan yang menjadi fungsi tertingginya adalah menuang adonan semen. Jika dilihat dari fungsi terendahnya mengapa menyalakan engine? Karena untuk memutar roda gigi. Mengapa memutar roda gigi? Karena untuk memutar pully. Mengapa memutar pully? Karena untuk memutar gentong. Mengapa memutar gentong? Supaya bisa memiringkan gentong. Mengapa memiringkan gentong? Untuk memudahkan memasukkan bahan dan mengaduk adonan semen. Mengapa mengaduk adonan semen? Untuk persiapan dituangkan dengan memiringkan gentong. Mengapa memiringkan gentong? Untuk menuang adonan semen. Jika dilihat dari fungsi tertingginya bagaimana menuang adonan semen? Dengan cara memiringkan gentong. Bagaimana memiringkan gentong? Dengan cara 
mengaduk semen terlebih dahulu. Bagaimana cara mengaduk semen? Dengan cara memasukkan bahan dan memiringkan gentong. Bagaimana memiringkan gentong? Dengan cara gentong diputar terlebih dahulu. Bagaimana memutar gentong? Dengan memutar pully. Bagaimana memutar pully? Dengan cara memutar roda gigi. Bagaimana memutar roda gigi? Dengan cara menyalakan engine

3. Komponen kritis pada mesin molen cor kapasitas $50 \mathrm{~kg}$ adalah knalpot, tabung solar, kerangka bawah, sirip pengaduk, pullry, dan roda pemindah.

4. Alternatif solusi yang dibangun untuk komponen knalpot adalah dipendekkan dan dihadapkan kebawah, untuk komponen tabung solar adalah tabung diganti dengan plastik dan posisinya ditinggikan, untuk komponen kerangka bawah adalah dengan diberi penguat pada bagian sikunya, untuk komponen sirip pengaduk adalah diberi lapisan penguat betoneser, untuk komponen pulley adalah ditambah satu pulley lagi (double pulley). Dan terakhir untuk komponen roda pemindah adalah dengan diberi tambahan roda pemindah dibagian depan.

5. Jika dibandingkan antara biaya kerugian sebelum dilakukan improvement dan sesudah dilakukan improvement, sangat berbeda jauh. Merujuk pada tabel 4.6 dimana biaya kerugian selama 6 bulan adalah Rp. 54.700.000. Sedangkan pada tabel 4.18 biaya kerugian selama 6 bulan setelah dilakukan reduksi menjadi Rp. 3.190.000. Selisih biaya kerugian sebelum dilakukan improvement dan sesudah dilakukan improvement adalah Rp. 51.510.000.

\section{Ucapan Terima Kasih (Acknowledgement)}

Penulis ucapan terimakasih kepada Bapak Ir. Hari Supriyanto, MSIE. Selaku dosen pembimbing penulis yang telah bersabar membimbing penulis sampai selesainya makalah ini, Ibu Suhartini, ST., MT., Bu Ni Luh Putu Hariastuti, ST., MT., Bapak Dr. Lukmandono, ST., MT. Selaku dosen penulis, Bapak Dr. Rony Prabowo, SE., ST., MT., MSM. Selaku ketua jurusan Teknik industri yang telah mengatur segalanya untuk mahasiswa, Bapak Mohamad Mujib selaku pembimbing penulis di lapangan (UD. Munajaya). Terimakasih juga kami sampaikan kepada kedua orang tua yang membantu dan mendo'akan penulis.

\section{Daftar Pustaka}

Bytheway, \& W., C. (2007). FAST Creativity \& Innovation: Rapidly Improving Processes, Product Development and Solving Complex Problems.

Harsita, P.A., Amam. (2019). Permasalahan Utama Usaha Ternak Sapi Potong di Tingkat Peternak dengan Pendekatan Vilfredo Pareto Analysis. Prosiding Seminar Nasional Teknologi Peternakan dan Veteriner.

Krisna, Ogik (2020) Rancang Bangun Mesin Molen Cor Mini. S-1 thesis, 021008 - Universitas Tridinanti Palembang

Younker, D. L. (2003). Value Engineering: Analysis and Methodology. Taylor \& Francis Group. 